\title{
Understanding the Role Diet Plays in Parkinson's Disease Could Lead to Better Disease Management
}

\author{
Jose A Santiago', Hope Bilyk ${ }^{2}$ and Judith A Potashkin ${ }^{1,3}$ \\ ${ }^{1}$ The Cellular and Molecular Pharmacology Department, The Chicago Medical School, USA \\ ${ }^{2}$ The Nutrition Department, The College of Health Professions, Rosalind Franklin University of Medicine and Science, North Chicago, IL, USA
}

Parkinson's disease (PD) is a progressive and incurable neurodegenerative disease of the central nervous system that usually develops in individuals after the age of 50 . PD is characterized by motor symptoms, including shaking, rigidity, slowness of movement and gait impairment, that are caused by the loss of dopaminergic neurons in substantia nigra pars compacta ( $\mathrm{SNpc}$ ) of the midbrain. Additional symptoms of the disease include autonomic dysfunction (i.e. gastrointestinal, urinary, sexual, orthostatic hypotension and excessive sweating), sleep problems, sensory problems and neuropsychiatric problems (i.e. depression, anxiety, dementia and psychosis) [1].

Most cases of PD are sporadic with an unknown etiology. Currently it is thought that environmental factors and genetic susceptibility are both important in disease development [2]. PD is characterized by mitochondrial dysfunction, inflammation, dysfunction of the autosomal-lysomal autophagy system [3] and endoplasmic reticulum stress [4]. The pathological manifestation of the disease is characterized by accumulation of alpha synuclein inclusions in neurons referred to as Lewy bodies [5].

Currently there is no cure for PD. Motor symptoms of the disease are most often treated using levodopa and dopamine agonists. As the disease progresses, more neurons are lost, the drugs become less effective and some patients develop disabling dyskinesias. In addition, several studies indicate an increasing risk of malnutrition among PD patients and that malnourished patients remain under-recognized by health professionals [6,7]. In fact, a recent study revealed that approximately $30 \%$ of patients with mild to moderate PD are at risk of malnutrition [7]. This finding suggests that PD patients with more severe symptoms may be at even higher risk of malnutrition.

Neuronal cell growth and development requires a wide range of nutrients including protein, iron, zinc, selenium iodine folate, vitamin $\mathrm{A}$, and long-chain polyunsaturated fatty acids [8]. A balance of these nutrients is necessary for both the developing and aging brain. The brain is vulnerable to nutritional insults as we age, which can sometimes lead to irreversible damage. For example, diets that are high in saturated fats are implicated in cognitive dysfunction and increased risk for neurological disease, whereas diets rich in omega 3 fatty acids may reverse these detrimental effects [9]. More broadly, the relationship between the brain and nutrition can be exemplified with the increased risk in neurological disease among patients suffering conditions associated with the metabolic syndrome. Specifically, patients with diabetes mellitus often develop neurodegenerative diseases such as PD and Alzheimer's disease (AD) [10-12]. Increasing evidence suggest that impaired insulin signaling and other common dysregulated processes lead to neurodegeneration.

Our understanding of the impact of nutrients in PD patients is in its infancy. Evidence from experimental and clinical medicine suggests that some nutrients may exert neuroprotective effects, whereas other dietary constituents may be detrimental for PD patients [13]. The impact of nutrients has been implicated in the biological pathways that mediate neurodegeneration including mitochondrial dysfunction, inflammation, and oxidative stress as well as in novel mechanisms that promote neuroprotection.
Nutritional constituents associated with a possible decreased risk of PD include phytochemicals present in fruits and vegetables. Fruits and vegetables rich in antioxidants including vitamin A, B and $\mathrm{C}$, and carotenoids may benefit PD patients and reduced disease risk $[14,15]$ reviewed in [13]. Vitamin D supplementation appears to be neuroprotective in models of PD [16,17]. These studies are partly based on the observation that vitamin $\mathrm{D} 3$ deficiency is highly prevalent among PD patients $[18,19]$. A phase 2 clinical trial is currently testing the effects of vitamin D3 on balance, gait, falls, strength and cognitive performance in PD patients (NCT01119131). Another ongoing clinical trial of vitamin $\mathrm{D}$ in PD is designed to determine whether vitamin D improves motor and cognitive functions of patients with PD (NCT00571285).

In addition, evidence from in vitro and animal models possibly indicate that omega-3 polyunsaturated fatty acids (PUFA) exert neuroprotective effects in PD [20,21]. Although the evidence from clinical trials is very limited, one study showed that supplementation with omega-3 PUFA reduced depression in PD patients [22]. Like depression, dyskinesias resulting from symptomatic treatments such as levodopa also have a great impact in the quality of life of PD patients [23]. A phase 1 clinical trial for PD is designed to evaluate omega-3 fatty acids for the treatment of levodopa induced dyskinesia (LID) in PD patients (NCT01563913).

Caffeine is perhaps the most widely studied neuroprotective agent in PD. Several lines of research strongly indicate that caffeine reduces dopaminergic toxicity through antagonism of adenosine $A_{2 A}$ receptors [24,25]. Increasing experimental and epidemiological evidence indicates that caffeine elicits neuroprotection and improves motor and non-motor symptoms in PD patients [26-28]. In this regard, an upcoming clinical trial will evaluate the efficacy of caffeine intake on the motor and non-motor aspects of PD (NCT01738718). In addition other compounds found in coffee including eicosanolyl-5hydroxytryptamide have shown promise as neuroprotective agents in animal studies and warrant further studies in humans.

In contrast, consumption of dairy products and milk appear to possibly increase risk of PD [29,30]. The detrimental effects may be explained by the presence of potential toxins in some dairy products. However, the specific component of milk or the underlying mechanism has not yet been determined. Thus, more rigorous studies including

*Corresponding author: Judith A Potashkin, Department of Cellular and Molecular Pharmacology, The Chicago Medical School, Rosalind Franklin University of Medicine and Science, 3333 Green Bay Rd, North Chicago, Illinois, 60064-3037, Tel: 847-578-8677; E-mail: judy.potashkin@rosalindfranklin.edu

Received November 25, 2014; Accepted November 26, 2014; Published December 01, 2014

Citation: Santiago JA, Bilyk H, Potashkin JA (2014) Understanding the Role Diet Plays in Parkinson's Disease Could Lead to Better Disease Management. Clin Exp Pharmacol 5: e135. doi:10.4172/2161-1459.1000e135

Copyright: (C) 2014 Santiago JA, et al. This is an open-access article distributed under the terms of the Creative Commons Attribution License, which permits unrestricted use, distribution, and reproduction in any medium, provided the original author and source are credited. 
organic dairy products are needed to assess the impact of dairy products and its constituents in neurodegeneration.

In additional to studies on individual nutrients, we also need more studies to determine whether specific diets may be beneficial for PD patients. Although the epidemiological evidence regarding the neuroprotective effects of fruits and vegetable is conflicting [15] recent studies suggest it may reduce risk of PD [14,31]. A current clinical trial is comparing the impact of a healthy high carbohydrate (50\% of daily calories) diet including fruits and vegetables to a low carbohydrate diet ( $\leq 20$ g per day) in PD (NCT00777010). Previously, a small feasibility study found that a ketogenic diet consisting of high fat and very low carbohydrate intake improved motor symptoms in PD patients [32] suggesting that this should also be tested in a clinical trial. Another promising diet for neurodegenerative diseases is the Mediterranean diet, characterized by the high intake of vegetables, legumes, fruits, grains, monounsaturated fatty acids, fish, low to moderate consumption of dairy products, meat and poultry and moderate consumption of red wine. Higher adherence to a Mediterranean diet has been associated with a reduced risk of cognitive decline and essential tremor [33,34], conditions associated with neurodegeneration. Furthermore, adherence to a Mediterranean diet may be associated with a reduced risk of PD, whereas low adherence is associated with an earlier age of onset [35].

In conclusion, our current state of knowledge about the role nutrients and diet play in PD is very limited. Because of these limitations physicians usually limit their dietary recommendations for patients to eat a well-balanced diet that includes increased fiber intake to prevent constipation. In addition, they may make medication-specific suggestions such as moderation in eating air-dried and fermented foods if the patient is taking a MAO-B inhibitor. Ideally, however, we would like to have a better understanding of how specific nutrients and diets influence the course of $\mathrm{PD}$ so that clinicians may provide more extensive recommendations. What we need are large randomized longitudinal clinical trials in order to establish which nutrients or diets are beneficial for PD patients. Ideally, these studies will take an integrative approach to analyze the data including genomics, transcriptomics and network analysis [36]. Incorporation of patients at risk for PD and individuals with a genetic predisposition to the disease in the trials will be crucial to identifying nutrients or diets that may slow the progress of the disease.

\section{References}

1. Goldman JG, Postuma R (2014) Premotor and nonmotor features of Parkinson's disease. Curr Opin Neurol 27: 434-441.

2. Warner TT, Schapira AH (2003) Genetic and environmental factors in the cause of Parkinson's disease. Ann Neurol 53 Suppl 3: S16-23; discussion S23-15.

3. Beal MF (2003) Mitochondria, oxidative damage, and inflammation in Parkinson's disease. Ann N Y Acad Sci 991: 120-131.

4. Ryu EJ, Harding HP, Angelastro JM, Vitolo OV, Ron D, et al. (2002) Endoplasmic reticulum stress and the unfolded protein response in cellular models of Parkinson's disease. J Neurosci 22: 10690-10698.

5. George S, Rey NL, Reichenbach N, Steiner JA, Brundin P (2013) alphaSynuclein: the long distance runner. Brain Pathol 23: 350-357.

6. Sheard JM, Ash S, Mellick GD, Silburn PA, Kerr GK (2013) Markers of disease severity are associated with malnutrition in Parkinson's disease. PloS one 8 : e57986.

7. Fereshtehnejad SM, Ghazi L, Sadeghi M, Khaefpanah D, Shahidi GA, et al. (2014) Prevalence of Malnutrition in Patients with Parkinson's Disease: A Comparative Study with Healthy Controls using Mini Nutritional Assessment (MNA) Questionnaire. J of Parkinsons Dis 4: 473-481.

8. Georgieff MK (2007) Nutrition and the developing brain: nutrient priorities and measurement. The American journal of clinical nutrition 85: 614S-620S.
9. Gomez-Pinilla $F(2008)$ Brain foods: the effects of nutrients on brain function Nature reviews Neuroscience 9: 568-578.

10. Santiago JA, Potashkin JA (2013) Shared dysregulated pathways lead to Parkinson's disease and diabetes. Trends Mol Med 19: 176-186.

11. Santiago JA, Potashkin JA (2014) System-based approaches to decode the molecular links in Parkinson's disease and diabetes. Neurobiol Dis 72: 84-91.

12. Santiago JA, Potashkin JA (2013) Integrative network analysis unveils convergent molecular pathways in Parkinson's disease and diabetes. PloS one 8: e83940.

13. Seidl SE, Santiago JA, Bilyk H, Potashkin JA (2014) The emerging role of nutrition in Parkinson's disease. Frontiers in aging neuroscience 6: 36 .

14. Okubo H, Miyake Y, Sasaki S, Murakami K, Tanaka K, et al. (2012) Dietary patterns and risk of Parkinson's disease: a case-control study in Japan. Eur J of Neurol: 19: 681- 688 .

15. Miyake Y, Fukushima W, Tanaka K, Sasaki S, Kiyohara C, et al. (2011) Dietary intake of antioxidant vitamins and risk of Parkinson's disease: a case-control study in Japan. Eur J of Neurol 18: 106-113.

16. Smith MP, Fletcher-Turner A, Yurek DM, Cass WA (2006) Calcitriol protection against dopamine loss induced by intra cerebroventricular administration of 6-hydroxydopamine. Neurochemical research 31: 533-539.

17. Wang JY, Wu JN, Cherng TL, Hoffer BJ, Chen HH, et al. (2001) Vitamin D(3) attenuates 6 -hydroxydopamine-induced neurotoxicity in rats. Brain research 904: $67-75$.

18. Ding H, Dhima K, Lockhart KC, Locascio JJ, Hoesing AN, et al. (2013) Unrecognized vitamin D3 deficiency is common in Parkinson disease: Harvard Biomarker Study. Neurology 81: 1531-1537.

19. Sato Y, Kikuyama M, Oizumi K (1997) High prevalence of vitamin D deficiency and reduced bone mass in Parkinson's disease. Neurology 49: 1273-1278.

20. Ozsoy O, Seval-Celik Y, Hacioglu G, Yargicoglu P, Demir R, et al. (2011) The influence and the mechanism of docosahexaenoic acid on a mouse model of Parkinson's disease. Neurochemistry international 59: 664-670.

21. Bousquet M, Saint PM, Julien C, Salem N, Cicchetti F, et al. (2008) Beneficia effects of dietary omega-3 polyunsaturated fatty acid on toxin-induced neuronal degeneration in an animal model of Parkinson's disease. FASEB J : 22: 1213 1225 .

22. da Silva TM, Munhoz RP, Alvarez C, Naliwaiko K, Kiss A, et al. (2008) Depression in Parkinson's disease: a double-blind, randomized, placebocontrolled pilot study of omega-3 fatty-acid supplementation. J Affect Disord 111: 351-359.

23. Pechevis $M$, Clarke CE, Vieregge $P$, Khoshnood $B$, Deschaseaux-Voinet $C$ et al. (2005) Effects of dyskinesias in Parkinson's disease on quality of life and health-related costs: a prospective European study. Eur $\mathrm{J}$ of Neuro 12 956-963.

24. Xiao D, Cassin JJ, Healy B, Burdett TC, Chen JF, et al. (2011) Deletion of adenosine $\mathrm{A}(1)$ or $\mathrm{A}((2) \mathrm{A})$ receptors reduces $\mathrm{L}-3,4$-dihydroxyphenylalanineinduced dyskinesia in a model of Parkinson's disease. Brain research 1367 310-318.

25. Sonsalla PK, Wong LY, Harris SL, Richardson JR, Khobahy I, et al. (2012) Delayed caffeine treatment prevents nigral dopamine neuron loss in a progressive rat model of Parkinson's disease. Exp Neurol 234: 482-487.

26. Ascherio A, Chen H, Schwarzschild MA, Zhang SM, Colditz GA, et al. (2003) Caffeine, postmenopausal estrogen, and risk of Parkinson's disease. Neurology 60: 790-795

27. Prediger RD (2010) Effects of caffeine in Parkinson's disease: from neuroprotection to the management of motor and non-motor symptoms Journal of Alzheimer's disease : JAD 20 Suppl 1: S205-220.

28. Palacios N, Gao X, McCullough ML, Schwarzschild MA, Shah R, et al. (2012) Caffeine and risk of Parkinson's disease in a large cohort of men and women. Movement disorders : Mov Disord 27: 1276-1282.

29. Park M, Ross GW, Petrovitch H, White LR, Masaki KH, et al. (2005) Consumption of milk and calcium in midlife and the future risk of Parkinson disease. Neurology 64: 1047-1051.

30. Kyrozis A, Ghika A, Stathopoulos P, Vassilopoulos D, Trichopoulos D, et al. (2013) Dietary and lifestyle variables in relation to incidence of Parkinson's disease in Greece. Eur J Epidemiol 28: 67-77. 
Citation: Santiago JA, Bilyk H, Potashkin JA (2014) Understanding the Role Diet Plays in Parkinson's Disease Could Lead to Better Disease Management. Clin Exp Pharmacol 5: e135. doi:10.4172/2161-1459.1000e135

31. Nielsen SS, Franklin GM, Longstreth WT, Swanson PD, Checkoway H (2013) Nicotine from edible Solanaceae and risk of Parkinson disease. Ann Neurol 74: $472-477$

32. Vanitallie TB, Nonas C, Di Rocco A, Boyar K, Hyams K, et al. (2005) Treatment of Parkinson disease with diet-induced hyperketonemia: a feasibility study. Neurology 64: 728-730.

33. Feart C, Samieri C, Rondeau V, Amieva H, Portet F, et al. (2009) Adherence to a Mediterranean diet, cognitive decline, and risk of dementia. JAMA 302: 638-648.
34. Scarmeas N, Louis ED (2007) Mediterranean diet and essential tremor. A casecontrol study. Neuroepidemiology 29: 170-177.

35. Alcalay RN, Gu Y, Mejia-Santana H, Cote L, Marder KS, et al. (2012) The association between Mediterranean diet adherence and Parkinson's disease. Movement disorders : Mov Disord 27: 771-774.

36. Santiago JA, Potashkin JA (2014) A network approach to clinical intervention in neurodegenerative diseases. Trends in molecular medicine. 